\title{
Various Textiles-Based Comparative Analysis of a Millimeter Wave Miniaturized Novel Antenna Design for Body-Centric Communications
}

\author{
Mohammad Monirujjaman Khan $\mathbb{D}^{1},{ }^{1}$ Kaisarul Islam $\mathbb{D}^{1},{ }^{1}$ Md. Nakib Alam Shovon $\mathbb{D}$, ${ }^{1}$ \\ Mehedi Masud $\mathbb{D}^{2},{ }^{2}$ Mohammed Baz $\mathbb{D}^{3}$, and Mohammed A. AlZain $\mathbb{D}^{4}$ \\ ${ }^{1}$ Electrical and Computer Engineering Department, North South University, Bashudndhara, Dhaka 1229, Bangladesh \\ ${ }^{2}$ Department of Computer Science, College of Computers and Information Technology, Taif University, P. O. Box 11099, \\ Taif 21944, Saudi Arabia \\ ${ }^{3}$ Department of Computer Engineering, College of Computers and Information Technology, Taif University, P. O. Box 11099, \\ Taif 21944, Saudi Arabia \\ ${ }^{4}$ Department of Information Technology, College of Computers and Information Technology, Taif University, P. O. Box 11099, \\ Taif 21944, Saudi Arabia
}

Correspondence should be addressed to Mohammad Monirujjaman Khan; monirujjaman.khan@northsouth.edu

Received 4 June 2021; Accepted 20 July 2021; Published 2 August 2021

Academic Editor: Muhammad Inam Abbasi

Copyright (c) 2021 Mohammad Monirujjaman Khan et al. This is an open access article distributed under the Creative Commons Attribution License, which permits unrestricted use, distribution, and reproduction in any medium, provided the original work is properly cited.

\begin{abstract}
A $60 \mathrm{GHz}$ compact and novel shaped microstrip-fed antenna based on a textile substrate for body-centric communications has been proposed in this paper. The antenna has a partial ground, and the textile substrate is made up of $1.5 \mathrm{~mm}$ thick $100 \%$ polyester. Two rectangular sections from the patch antenna's radiator were removed to give the antenna a swan-shaped appearance. The antenna was designed and simulated using computer simulation technology (CST) microwave studio software. Simulated results show that, in free-space, the antenna achieved a high bandwidth of $11.6 \mathrm{GHz}$ with a center frequency of $60.01 \mathrm{GHz}$. With $89.4 \%$ radiation efficiency, the maximum gain of the antenna was $8.535 \mathrm{dBi}$. For the on-body scenario, the antenna was simulated over five different distances from a human torso phantom. At the closest distance from the phantom, the antenna's gain was $5.27 \mathrm{dBi}$, while the radiation dropped significantly to $63 \%$. The highest bandwidth of $12.27 \mathrm{GHz}$ was attained at $8 \mathrm{~mm}$, while the lowest bandwidth of $5.012 \mathrm{GHz}$ was attained at $4 \mathrm{~mm}$ away from the phantom. Gain and radiation efficiency were comparable to freespace results at the furthest distance. The antenna was also simulated with ten different textile substrates for both free-space and on-body scenarios. Among these ten substrates, denim, tween, and Quartzel fabric had similar performance results as polyester. This design achieved similar performance compared to other $60 \mathrm{GHz}$ textile antennas while being a bit more compact. This antenna will be a promising choice for body-centric communications because of its compact size, textile-based substrate, and excellent on-body performance.
\end{abstract}

\section{Introduction}

Advances in wireless technologies have meant an exponential increase in demand for smart wireless devices for the last few decades. These devices include emerging wearables for health and fitness. In today's world, the expectation of having every device connected to a network for the transfer of a huge amount of data is quite the norm. Due to this ever- increasing demand for connectivity, it is apparent that current wireless bands are getting congested, and future communication will have to be in the millimeter-wave ( $\mathrm{mm}$ wave) spectrum [1, 2].

The mm-wave spectrum consists of frequencies between 30 to $300 \mathrm{GHz}$, which means the spectrum has a wavelength range from $10 \mathrm{~mm}$ to $1 \mathrm{~mm}$. In free space, $\mathrm{mm}$-wave has slightly higher attenuation than $4 \mathrm{G}$ frequencies due to high 
oxygen absorption. At 60,180 , and $380 \mathrm{GHz}$ frequency bands, the attenuation of mm-wave is significantly higher. Short wavelength and higher attenuation mean communication in the mm-waves spectrum is suitable for short-range indoor obstacle-free applications [1]. The Federal Communications Commission (FCC) allocated the $60 \mathrm{GHz}$ band for unlicensed use in $2001[3,4]$. Currently, the $60 \mathrm{GHz}$ band is used for Wireless Gigabit Alliance (WiGig) wireless local area network (WLAN) devices. The $60 \mathrm{GHz}$ band $(57-64 \mathrm{GHz})$ offers a very high data rate in the gigabit per second range [3].

Wearable devices work in the vicinity of body-centric wireless communications (BCWC). BCWC includes wireless body area network (WBAN), a network of sensors around the human body. Wearable devices under WBAN have three modes of operation: on-body, off-body, and in-body. Communication between wearable devices placed in close proximity to the human body is known as on-body communication. Off-body communication is between a device placed on the human body and another device placed a few meters away from the human body. When an implant sends data to a device placed outside of the human body, it is known as in-body communication [2]. Body-centric devices may consist of medical equipment for monitoring health conditions such as heart rate and blood pressure [5]. Such devices designed for working in the $60 \mathrm{GHz}$ band will have very directional and small antennas in physical size [3].

Textile antennas for WBAN are an attractive design prospect for their potential wearable uses. In general, these antennas are made from flexible conductive materials known as electro-textiles and substrate materials. Electrotextiles are made by weaving or knitting conductive threads like copper with nonconductive fabric materials. The substrate is a nonconductive material usually made of regular fabrics such as denim, polyester, and cotton. Textile antennas are practical due to their ease of integration into different fabrics, making them suitable for hospital patients' clothing, rescue workers' clothing, etc. The construction of textile antennas makes them low profile, lightweight, and low maintenance $[6,7]$.

Antennas designed for body-centric communication need to be evaluated appropriately under comparable human body conditions. The human body acts as a lossy medium, and it can greatly degrade the antennas' performance [8]. In [9-12], narrowband and ultra wideband antenna designs have been discussed by various authors. For these cases, none of the antennas are designed on a textile substrate. However, in [13-15], the authors presented $60 \mathrm{GHz}$ antennas that are not designed on textile substrates. In addition, there are very few mm-wave antenna designs presented in [16-19]. In [15], a $60 \mathrm{GHz}$ body-centric antenna is designed for on-body operation. In free space, the antenna achieved a high gain of $9.37 \mathrm{~dB}$ with a bandwidth of $5 \mathrm{GHz}$. For on-body performance evaluation, a phantom of the human torso was created. Even though mm-waves have a very low penetration depth on the human body, the phantom was created, taking skin, fat, and muscle layers. As a result, the antenna produced a slightly lower bandwidth but a higher maximum gain. Puskley et al. designed a disc- like low-profile antenna that is well matched between 59.3 and $63.4 \mathrm{GHz}$ [16]. The antenna lost about 25\% efficiency when kept $1 \mathrm{~mm}$ away from a $5 \mathrm{~mm}$ thick skin phantom. Similar to the previous paper, depending on the antenna's distance from the phantom, the on-body maximum gain increased compared to free space. A low-profile slotted patch $60 \mathrm{GHz}$ antenna was designed in [17]. The antenna has a wide bandwidth of $9.8 \mathrm{GHz}$ with $74 \%$ efficiency in free space. For the on-body scenario, the antenna's efficiency decreased to $63 \%$, but again, like in previous cases, the gain increased from $10.6 \mathrm{dBi}$ to $12.1 \mathrm{dBi}$. The abovementioned mm-wave antennas are not textile based.

A $60 \mathrm{GHz}$ textile antenna based on a microstrip patch array is proposed in [18]. Due to the fabrication process's complexity, instead of electro-textiles, copper foils of $0.07 \mathrm{~mm}$ were used for all radiating materials. For textile material, only a cotton-woven fabric of $0.2 \mathrm{~mm}$ was used. The antenna was fed by a $15.2 \mathrm{~mm}$-long microstrip line and a $\mathrm{V}$ connector for performance measurements. The reflection coefficients were lower than $-10 \mathrm{~dB}$ in the $57-64 \mathrm{GHz}$ range with $40.7 \%$ efficiency in free space. For human body performance, the antenna was kept at 0 and $5 \mathrm{~mm}$ away from a skin phantom of size $2 \times 100 \times 100 \mathrm{~mm}^{3}$. At the closest distance from the phantom, both the efficiency and gain of the antenna decreased. At $5 \mathrm{~mm}$ away from the phantom, these values increased closer to free-space values. The antenna was also subject to bending and crumpling, both of which had little effect on the antenna's performance. In [19], a similar sort of analysis has been made on a microstrip-fed Yagi-Uda antenna. The antenna consists of a driven dipole and 10 directors printed on a $0.2 \mathrm{~mm}$ thick fabric made of cotton. For the previously mentioned reason, the radiators are made from $0.07 \mathrm{~mm}$ thick copper foil. The antenna produced an end-fire radiation pattern over the $55-64 \mathrm{GHz}$ range. Computed and measured maximum gain in free space was around $9.2 \mathrm{dBi}$. The antenna was evaluated on a homogeneous skin-equivalent phantom measuring $10 \times 100 \times 100 \mathrm{~mm}^{3}$ at two different distances like in [18]. Compared to free space, the antenna's efficiency dropped to $48 \%$ from $78 \%$, while the gain increased to $11.9 \mathrm{dBi}$. These two antennas are designed for only cotton substrates $[18,19]$. One was designed for $60 \mathrm{GHz}$ array antennas and another one was designed to get end-fire radiation.

Most of the studies conducted for the wearable textile antenna are based on designs working in much lower frequency bands [20-27]. Although the antennas presented in $[18,19]$ are textile based, they are designed for only one textile material, cotton. The antenna presented in [18] was an array antenna. The objectives and research investigation of the work $[18,19]$ are different from the research objectives and investigation of this paper. This paper's main objective is to propose a design of a $60 \mathrm{GHz}$ antenna based on a $100 \%$ polyester substrate for wearable devices. Various textilesbased comparative analysis of a millimeter wave miniaturized novel antenna design for body-centric communications is presented here. The performance of the antenna has been compared with ten different textile substrates. Parametric studies are performed by changing various antenna parameters. The on-body performance was also investigated. In 
addition, the performance also investigated placing the antenna at different distances from the human body model. Finally, the on-body performance of the antenna for various substrates has been investigated and compared.

This paper consists of six sections. The antenna's structure and its material selection are given in Section 2. Free-space performance is described in Section 3. Parametric changes were made where lengths of different parts of the antenna are altered to observe performance changes. The polyester textile substrate was replaced with ten other substrates and evaluated in free space. The simulation results are included in Section 3. For the wearable scenario, the antenna was placed over a torso phantom at 5 different distances. The on-body simulation results are detailed in Section 4. On-body simulation results for other textile substrates closest to the phantom are also included in this section. In Section 5, a brief comparison of the proposed antenna has been made with other available $60 \mathrm{GHz}$ textiles. Lastly, in Section 6, conclusions are made.

\section{Materials and Antenna Design}

To minimize losses in wearable scenarios, an appropriate design should be considered for textile antennas. The antenna should be of low-profile and flexible enough so that the performance does not significantly degrade under stress [7]. This paper proposes the design of a microstrip patch antenna with the partial ground (Figures $1(\mathrm{a})-1(\mathrm{~d})$ ). Instead of electro-textile, the radiating patch and ground of the antenna are made of perfect electric conductor (PEC) with $0.035 \mathrm{~mm}$ thickness. The textile substrate is made of $1.5 \mathrm{~mm}$ thick $100 \%$ polyester, which has a dielectric constant of 1.9 . The dielectric constant is the real part of relative permittivity and is an important parameter as it affects the impedance bandwidth of the antenna. Low dielectric constant reduces surface wave losses within a substrate and hence increases impedance bandwidth [7]. The overall dimension of the textile substrate is $12.2 \times 12 \times 1.57 \mathrm{~mm}^{3}$. The electrical size of the antenna for the overall width and length of the substrate is $0.42 \lambda$ and $0.41 \lambda$, respectively. The antenna is fed by a $4.9 \mathrm{~mm}$-long and $2.15 \mathrm{~mm}$-wide microstrip line. The list of antenna materials and their thickness and dielectric constant are given in Table 1. The antenna is designed and simulated using computer simulation technology (CST).

The antenna's radiating patch has a $7.3 \mathrm{~mm} \times 12 \mathrm{~mm}$ dimension and is connected to a $2.15 \mathrm{~mm}$-wide $4.9 \mathrm{~mm}$-long feedline. The electrical size of the antenna for the overall width and length of the radiating element is $0.68 \lambda$ and $0.42 \lambda$, respectively. The ground measures $4.5 \mathrm{~mm} \times 12 \mathrm{~mm}$. Two rectangular patches have been cut from the middle and right-hand sides of the radiator. The removed middle section from the patch has a $5.38 \mathrm{~mm} \times 2.9 \mathrm{~mm}$ dimension, while the removed section from the side is $6.3 \mathrm{~mm} \times 3.1 \mathrm{~mm}$. The removed radiator sections also give the antenna a swanshaped design. The total dimension of every section of the antenna is marked in Figure 1(c), and the values are given in Table 2.

\section{Free-Space Simulation Results}

Figure 2 shows the return loss curves of the proposed textile antenna. The antenna produced a very wide $-10 \mathrm{~dB}$ impedance bandwidth of $11.632 \mathrm{GHz}$ with a center frequency of $60.01 \mathrm{GHz}$ in free-space conditions. The antenna shows a very good return loss value of close to $-19 \mathrm{~dB}$ at the operating frequency. With a radiation efficiency of $89.4 \%$, the antenna achieved a maximum gain of $8.535 \mathrm{~dB}$, as shown in Table 3. Figure $3(\mathrm{a})$ shows the $3 \mathrm{D}$ radiation pattern at $60 \mathrm{GHz}$, while the E-plane and H-plane radiation patterns are shown in Figures 3(b) and 3(c), respectively. The radiation pattern of this antenna shows nearly omnidirectional radiation patterns with slight distortion at various angles. This could be due to the lower ground plane of the backside of this antenna. The antenna's E- and H-plane radiation patterns at $60 \mathrm{GHz}$ are shown to have good characteristics, except for slight null and few angles. The voltage standing wave ratio (VSWR) is shown in Figure 4. The figure shows that the antenna has a VSWR value at $60 \mathrm{GHz}$, close to 1.3 , which is excellent. For a surface, the current distribution is shown in Figure 5.

3.1. Parametric Studies. For the parametric study, the antenna's feedline width $(\mathrm{fw})$, length $(l)$, and ground length $(\mathrm{lg})$ were changed to observe the changes in the return loss curve. The rectangular patch size removed from the middle section was also varied by changing the values of the variables "ls" and "ws."

3.1.1. Feedline Width $(f w)$. The center frequency shifted slightly towards the right to $60.164 \mathrm{GHz}$ when the feedline width was made smaller from $2.15 \mathrm{~mm}$ to $2 \mathrm{~mm}$. Bandwidth decreased by $300 \mathrm{MHz}$ while both gain and radiation efficiency remained virtually unchanged. When the feedline width was increased to $2.5 \mathrm{~mm}$, the center frequency shifted to the left to $59.66 \mathrm{GHz}$. The bandwidth significantly increased by more than $1 \mathrm{GHz}$ when compared to free space. Gain remained unchanged for both smaller and larger widths. While the radiation efficiency slightly increased for feedline width. Figure 6 shows a return loss comparison curve for different feedline widths with the free-space result. Table 3 contains the detailed values of the parameters for feedline width changes.

3.1.2. Total Length of Antenna (l). When the antenna " $l$ " length was decreased from $12.2 \mathrm{~mm}$ to $12 \mathrm{~mm}$, a shift of the center frequency to the right was observed (Figure 7). Bandwidth remained unchanged, but both gain and radiation efficiency marginally increased. For a larger antenna length of $12.5 \mathrm{~mm}$, the center frequency shifted significantly to $58.834 \mathrm{GHz}$. All three parameters, bandwidth, gain, and radiation efficiency, decreased slightly. The details are given in Table 4 , and the return loss comparison curves are given in Figure 7. 


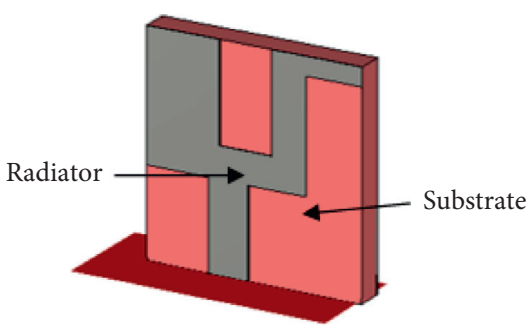

(a)

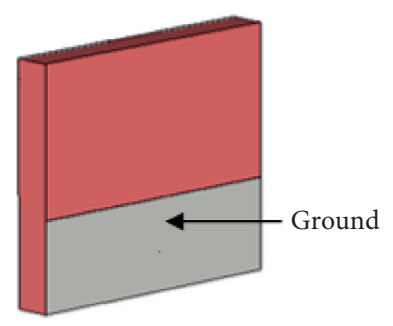

(b)

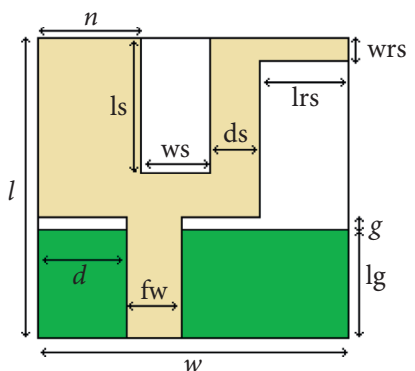

(c)

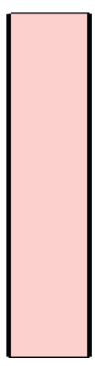

(d)

Figure 1: (a) Perspective front view; (b) perspective back view; (c) antenna dimensions; (d) left view.

TABLE 1: Antenna parts and materials.

\begin{tabular}{lccc}
\hline Antenna part & Thickness $(\mathrm{mm})$ & Material & Dielectric constant \\
\hline Ground & 0.035 & PEC & - \\
Substrate & 1.5 & $100 \%$ polyester & 1.9 \\
Patch radiator & 0.035 & PEC & - \\
\hline
\end{tabular}

TABLE 2: Antenna dimensions.

\begin{tabular}{lc}
\hline Parameter & Value $(\mathrm{mm})$ \\
\hline$w$ & 12 \\
$l$ & 12.2 \\
$\lg$ & 4.5 \\
$g$ & 0.4 \\
$d$ & 3.5 \\
fw & 2.15 \\
$n$ & 4.1 \\
ls & 5.38 \\
lrs & 3.1 \\
ws & 2.9 \\
wrs & 1
\end{tabular}

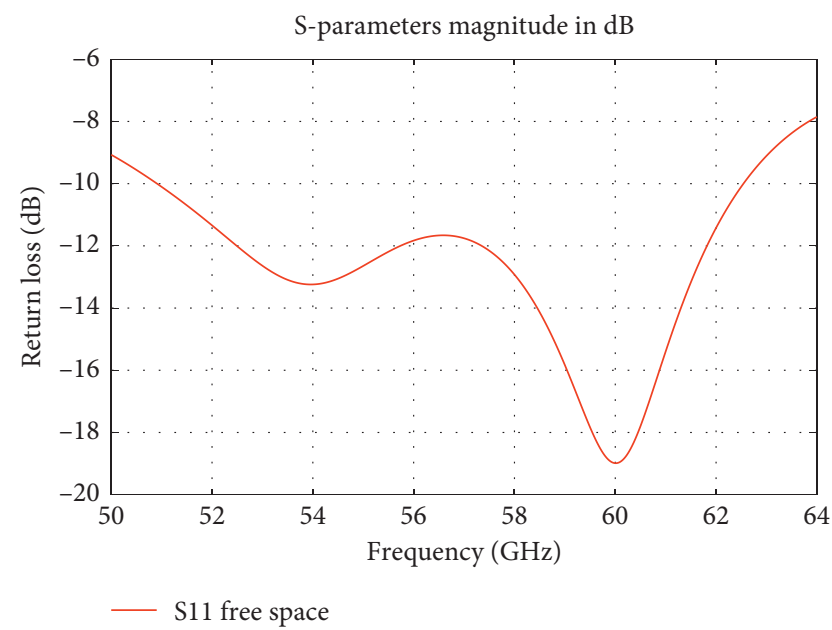

FIgURE 2: Return loss of the antenna in free space.

3.1.3. Ground Plane Length $(\mathrm{lg})$. Decreasing the size of the ground length, $\mathrm{lg}$, by $0.5 \mathrm{~mm}$, made the center frequency shift to the right while increasing the impedance bandwidth
(Figure 8). Gain remained unchanged, but the radiation efficiency decreased by more than $1 \%$. Opposite observations were made when the size of the ground length was increased. The center frequency shifted to the left, bandwidth decreased by $0.6 \mathrm{GHz}$ (Figure 8), radiation efficiency increased, and the gain remained almost the same (Table 5).

3.1.4. Length "ls" and Width "ws". Figures 9(a) and 9(b) show the return loss for change in radiator dimension. A huge shift of the center frequency to the left was observed when the length "ls" was decreased from $5.38 \mathrm{~mm}$ to $5 \mathrm{~mm}$ (Figure 9(a)). Even though both bandwidth and gain increased, the radiation efficiency decreased slightly. Very few changes were observed when the length was increased to $5.5 \mathrm{~mm}$. Altering the width "ws" from $2.9 \mathrm{~mm}$ to $2.6 \mathrm{~mm}$ and $3.2 \mathrm{~mm}$ had an insignificant effect on all four parameters. Table 6 shows all the detailed values from these changes.

3.2. Simulation Results Using Different Textiles. The antenna's polyester substrate was replaced by 10 different fabrics to analyze the antenna design in free-space further. These fabrics are as follows: Jeans, Denim, Silk, Tween, Panama, Felt, Moleskin, Cotton, Quartzel Fabric, and Cordura/Lycra. The dimensions of these substrates were kept the same as $100 \%$ polyester, but the thickness was altered depending on the fabric used. Results indicate that denim, tween, and quartzel fabric performed closest to the initial design in terms of center frequency and bandwidth (Figure 10(a)). Except for cordura/lycra, the gain was above $8 \mathrm{dBi}$ for all the substrates. Due to the similar thickness and relative permittivity of jeans and quartzel fabric, the results were very similar to polyester fabric. A summary of this fabric variation free-space analysis is given in Table 7. Figures 10(b) and $10(\mathrm{c})$ show the antenna's $\mathrm{E}$ and $\mathrm{H}$ plane radiation patterns for different textile substrates. Due to different textile substrates, the $\mathrm{E}$ and $\mathrm{H}$ plane radiation patterns do 
TABLE 3: Feedline width ( $\mathrm{fw}$ ) changes.

\begin{tabular}{lccc}
\hline Parameters & Free-space $\mathrm{fw}=2.15 \mathrm{~mm}$ & $\mathrm{fw}=2 \mathrm{~mm}$ & $\mathrm{fw}=2.5 \mathrm{~mm}$ \\
\hline Center frequency $(\mathrm{GHz})$ & 60.01 & 60.164 & 59.66 \\
Bandwidth $(\mathrm{GHz})$ & 11.632 & 11.302 & 12.354 \\
Gain $(\mathrm{dBi})$ & 8.535 & 8.54 & 8.523 \\
Radiation efficiency (\%) & 89.4 & 89.3 & 89.61 \\
\hline
\end{tabular}

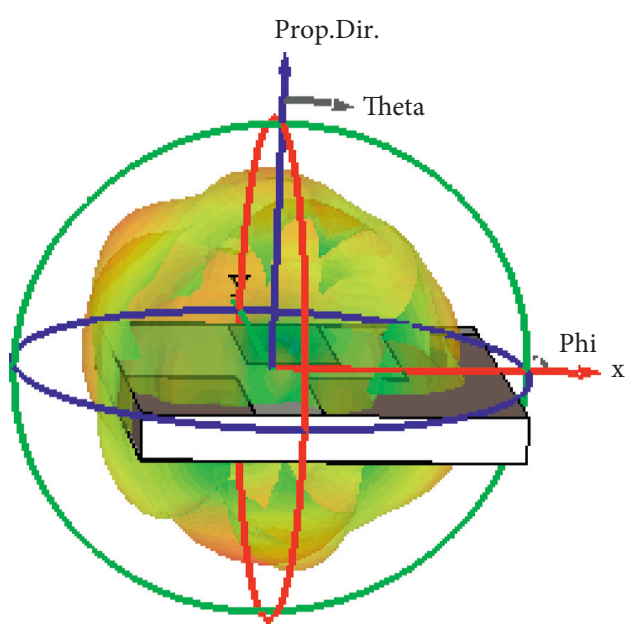

(a)

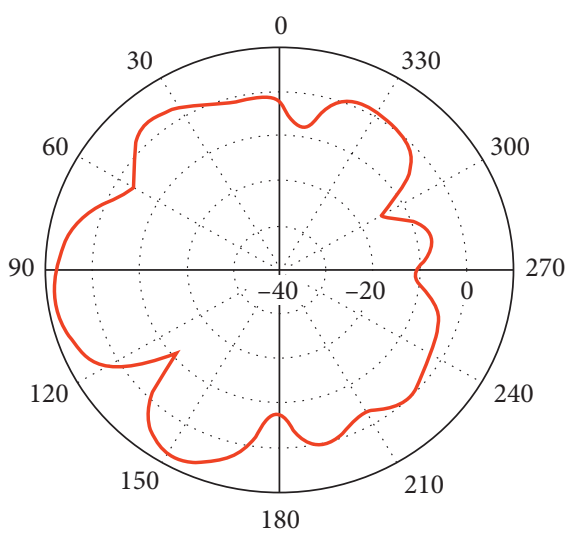

_- E-free space

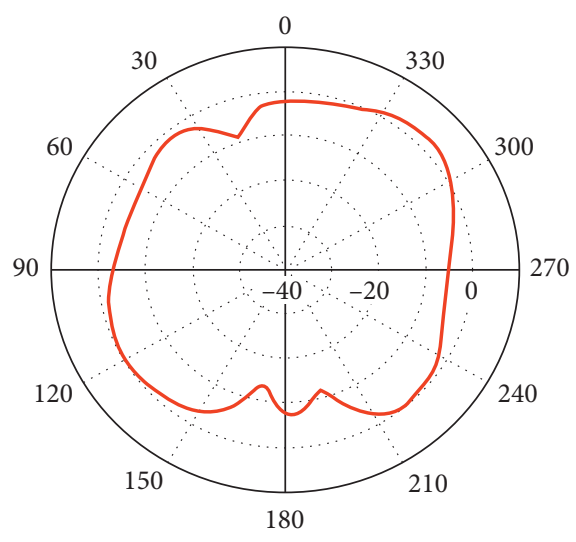

(b)

— H-free space

(c)

Figure 3: (a) 3D radiation pattern free space for $60 \mathrm{GHz}$, (b) E-plane radiation pattern free space for $60 \mathrm{GHz}$, and (c) H-plane radiation pattern free space for $60 \mathrm{GHz}$.

not change much, but a slight variation of power level is observed.

\section{On-Body Simulation Results}

For body-centric simulations, a human torso-equivalent phantom is created. This phantom contains three layers representing skin, fat, and muscle. mm-waves have very low penetration capability, and at $60 \mathrm{GHz}$, they can penetrate only $0.5 \mathrm{~mm}$ of human skin [15]. For this reason, most of the research works for $60 \mathrm{GHz}$ are based on skin- equivalent phantom $[18,19]$. We have chosen three layers for our work to represent a more accurate model of the human body. These three layers can be modeled accurately by taking their relative permittivity and conductivity. In Table 8 , detailed values of the dimensions, relative permittivity, and conductivity of the torso phantom are given [28]. Figure 11(a) shows the different layers of the human torso phantom.

The antenna was positioned at 5 different distances from the phantom to analyze the antenna's performance in wearable scenarios. Starting from $2 \mathrm{~mm}$, the antenna was 


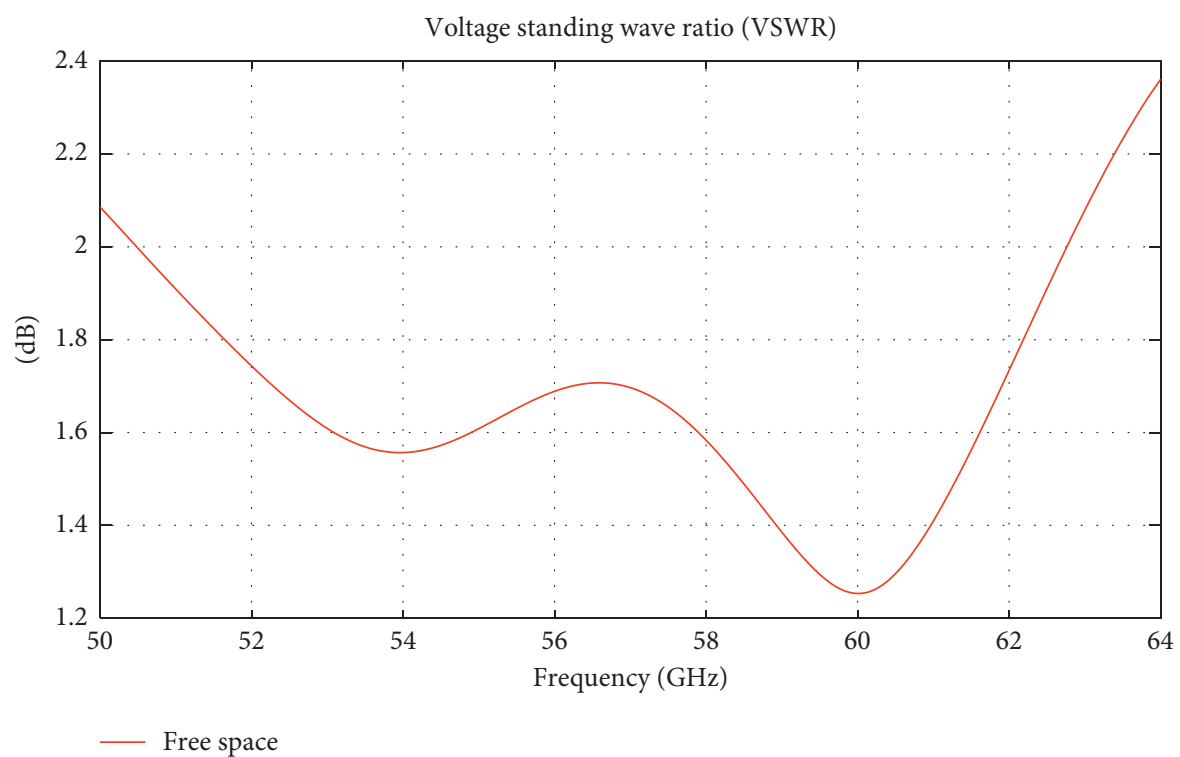

Figure 4: VSWR of the antenna at $60 \mathrm{GHz}$.

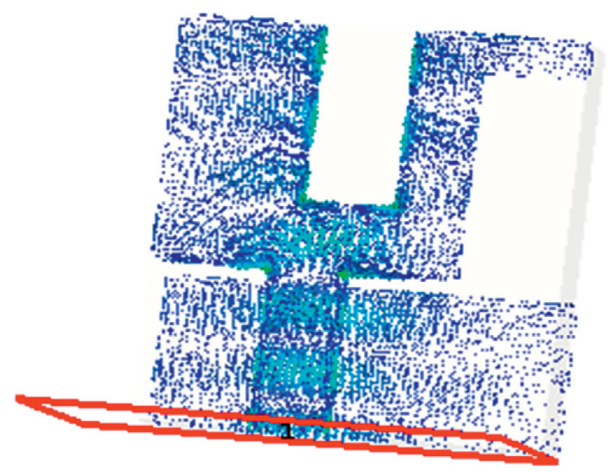

FIGURE 5: Free-space surface current distribution for $60 \mathrm{GHz}$.

moved gradually $2 \mathrm{~mm}$ away and ended up $10 \mathrm{~mm}$ away from the phantom. Figures 11(b)-11(d) show the antenna's position at three different distances.

4.1. 100\% Polyester Results. The return loss curves for different antenna placement distances from the three layers of the human body model are shown in Figure 12(a). At $2 \mathrm{~mm}$ and $6 \mathrm{~mm}$ away from the phantom, the center frequency of the antenna shifted by around $0.5 \mathrm{GHz}$. The shift was not as significant for 4,8 , and $10 \mathrm{~mm}$, while at $10 \mathrm{~mm}$, the center frequency was closest to the free-space center frequency. From distances of $6 \mathrm{~mm}$ and above, the impedance bandwidth was over $11 \mathrm{GHz}$, with $8 \mathrm{~mm}$ having the highest bandwidth. The bandwidth was lowest at $4 \mathrm{~mm}$, and at $2 \mathrm{~mm}$, it was just above $10 \mathrm{GHz}$. The maximum gain was around $8.7 \mathrm{dBi}$ for distances of 6,8 and $10 \mathrm{~mm}$. At $2 \mathrm{~mm}$, the gain dropped to a minimum value of $5.27 \mathrm{dBi}$. Radiation efficiency increased as the antenna's distance from the phantom increased but was significantly lower compared to free-space. In this study, it is noted that the antenna's onbody radiation efficiency is slightly lower than free space. This happens due to the absorption of different lossy tissues of the human body. From Table 9, it is noted that the reduction of radiation efficiency is lower when the distance between the antenna and the body increases. This happens because when the antenna is placed at a higher distance from the human body, it has less effect on the radiation efficiency from lossy human tissues. Table 9 summarizes the results of on-body antenna performance with distance variation. E-Plane and $\mathrm{H}$-plane radiation pattern with distance variation are shown in Figures 12(b) and 12(c). The radiation patterns for $\mathrm{E}$ and $\mathrm{H}$ planes do not change much for changing the distance between the antenna and the human body model, whereas the variation of power loss is observed.

4.2. Different Textile Results. All ten substrates were also simulated for an on-body scenario by keeping the antenna $2 \mathrm{~mm}$ away from the phantom. Antenna's performance 


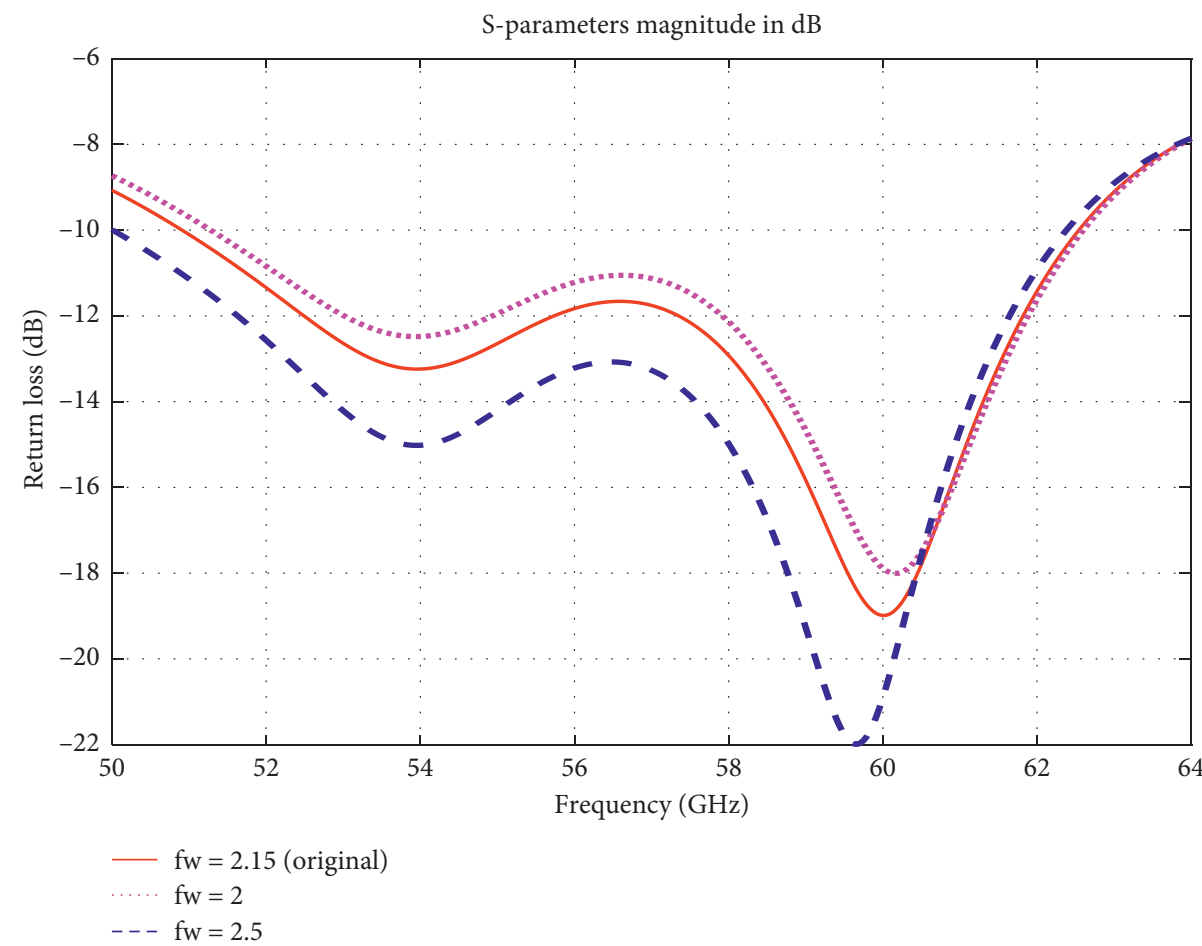

Figure 6: Return loss for different feedline widths.

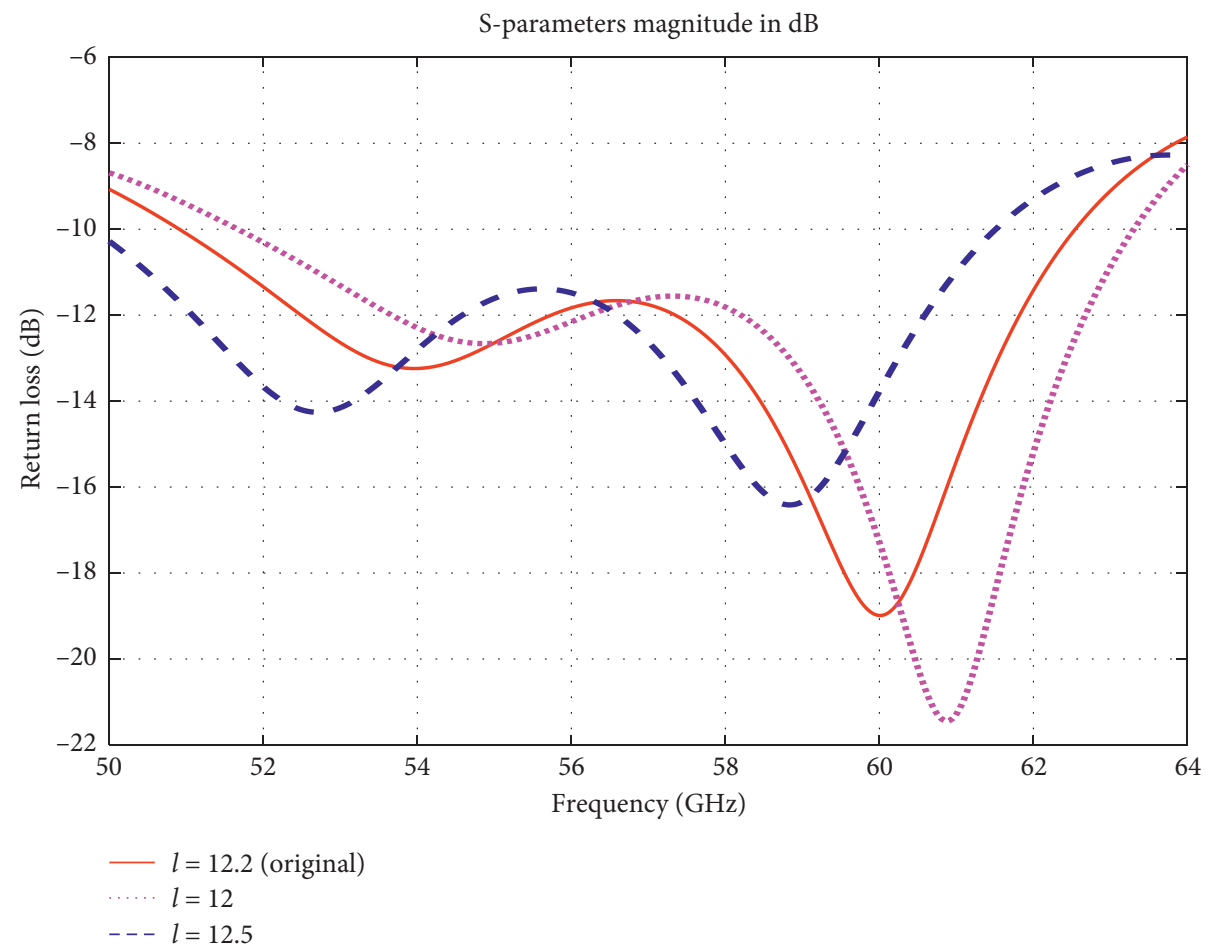

Figure 7: Return loss for change in antenna length "l."

TABLE 4: Antenna length changes.

\begin{tabular}{lccc}
\hline Parameters & Free-space $l=12.2 \mathrm{~mm}$ & $l=12 \mathrm{~mm}$ & $l=12.5 \mathrm{~mm}$ \\
\hline Center frequency $(\mathrm{GHz})$ & 60.01 & 60.878 & 58.834 \\
Bandwidth (GHz) & 11.632 & 11.63 & 11.505 \\
Gain $(\mathrm{dBi})$ & 8.535 & 8.622 & 8.235 \\
Radiation efficiency (\%) & 89.4 & 89.62 & 88.79 \\
\hline
\end{tabular}




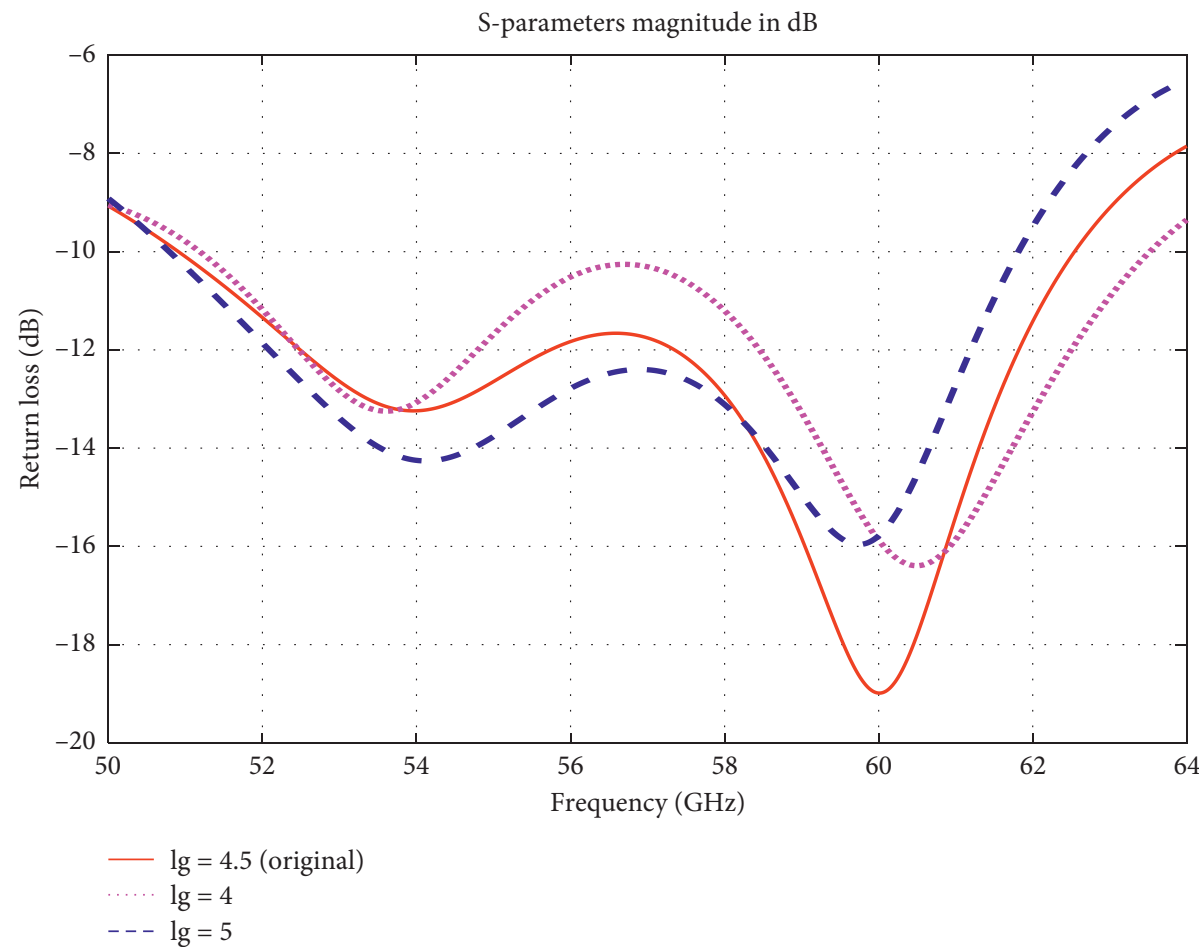

FIGURE 8: Return loss for change in ground length "lg."

TABLE 5: Ground plane length changes.

\begin{tabular}{lccc}
\hline Parameters & Free-space $\lg =4.5 \mathrm{~mm}$ & $\lg =4 \mathrm{~mm}$ & $\lg =5 \mathrm{~mm}$ \\
\hline Center frequency $(\mathrm{GHz})$ & 60.01 & 60.5 & 59.744 \\
Bandwidth $(\mathrm{GHz})$ & 11.632 & 12.345 & 11.018 \\
Gain $(\mathrm{dBi})$ & 8.535 & 8.555 & 8.692 \\
Radiation efficiency (\%) & 89.4 & 88.1 & 89.87 \\
\hline
\end{tabular}

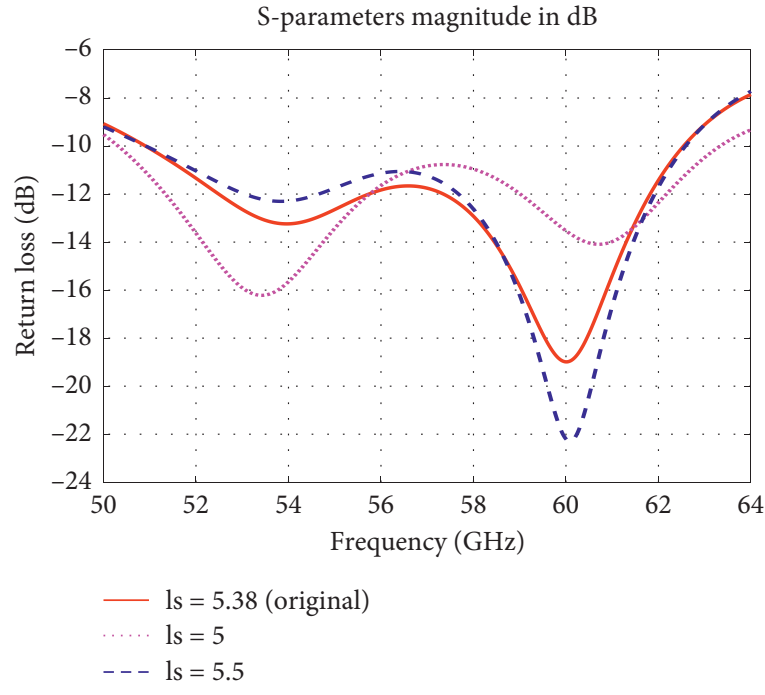

(a)

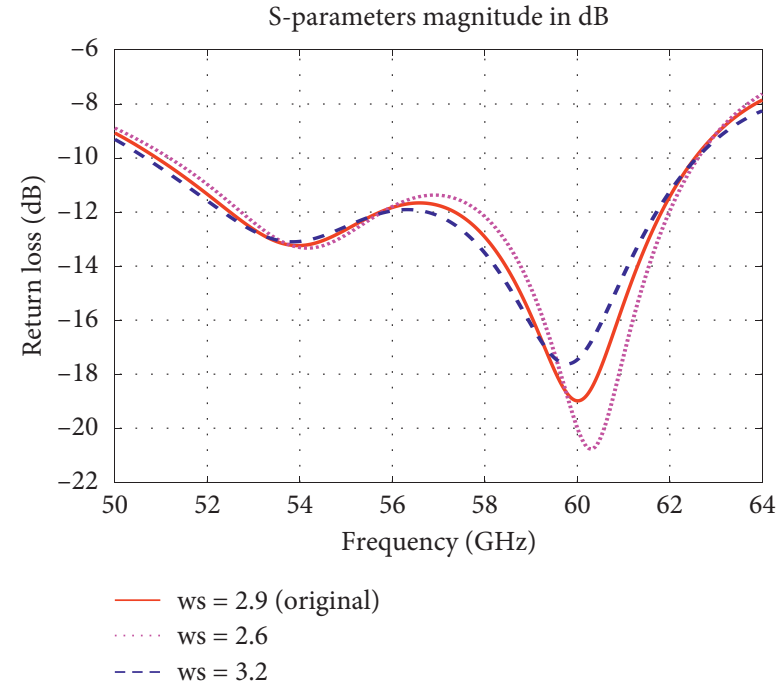

(b)

FIgURE 9: Return loss for change in radiator dimension. (a) "ls." (b) “ws." 
TABLE 6: Radiator length (ls) and width (ws) change.

\begin{tabular}{|c|c|c|c|c|c|}
\hline Parameters & Free space & ls $=5$ & ls $=5.5$ & $\mathrm{ws}=2.6$ & $\mathrm{ws}=3.2$ \\
\hline Center frequency $(\mathrm{GHz})$ & 60.01 & 53.416 & 60.08 & 60.29 & 59.772 \\
\hline Bandwidth $(\mathrm{GHz})$ & 11.632 & 13.002 & 11.657 & 11.427 & 11.894 \\
\hline Gain $(\mathrm{dBi})$ & 8.535 & 8.94 & 8.523 & 8.323 & 8.854 \\
\hline Radiation efficiency (\%) & 89.4 & 88.75 & 89.42 & 89.47 & 89.49 \\
\hline
\end{tabular}

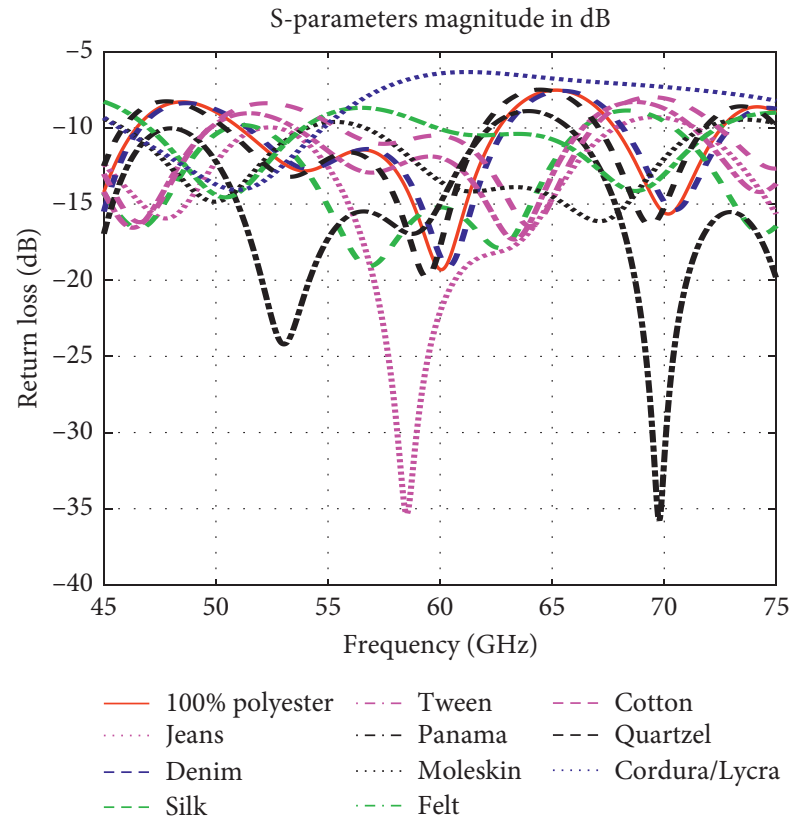

(a)

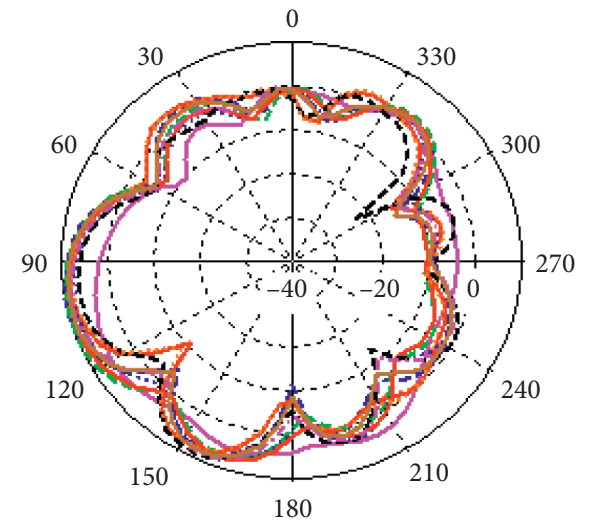

E-plane

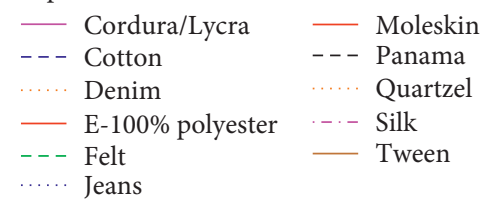

(b)

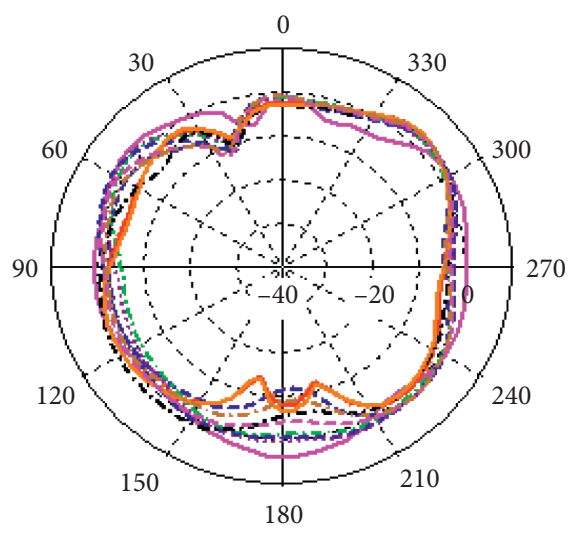

H-plane

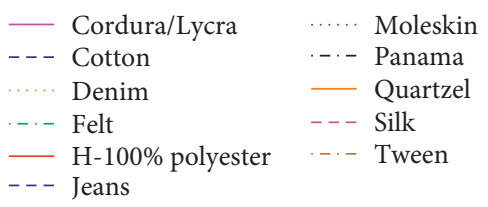

(c)

FIGURE 10: Comparison of antenna performance for different textile substrates in free-space (a) return loss (b) E-plane radiation patterns (c) $\mathrm{H}$-plane radiation patterns. 
TABLE 7: Free-space performance summary of the antenna for different textiles.

\begin{tabular}{|c|c|c|c|c|c|c|}
\hline Substrate & Relative permittivity & Thickness (mm) & Center frequency $(\mathrm{GHz})$ & Bandwidth $(\mathrm{GHz})$ & Gain (dBi) & $\begin{array}{c}\text { Radiation } \\
\text { efficiency (\%) }\end{array}$ \\
\hline $100 \%$ polyester & 1.9 & 1.5 & 60.06 & 11.578 & 8.531 & 89.69 \\
\hline Jeans & 1.7 & 1 & 58.5 & 15.094 & 7.841 & 93.19 \\
\hline Denim & 1.87813 & 1.5 & 60.36 & 11.505 & 8.653 & 89.91 \\
\hline Silk & 1.75 & 1.16 & 56.82 & 14.439 & 8.298 & 92.33 \\
\hline Tween & 1.69 & 1.37 & 60.3 & 12.818 & 9.138 & 91.88 \\
\hline Panama & 2.12 & 1.04 & 53.069 & 14.184 & 8.864 & 91.48 \\
\hline Felt & 1.38 & 1.38 & 68.772 & 12.507 & 9.824 & 93.64 \\
\hline Moleskin & 1.45 & 1.17 & 67.11 & 15.141 & 8.862 & 93.87 \\
\hline Cotton & 1.63 & 1.5 & 64.05 & 11.357 & 9.686 & 91.58 \\
\hline Quartzel fabric & 1.95 & 1.5 & 59.4 & 11.515 & 8.217 & 89.16 \\
\hline Cordura/Lycra & 1.5 & 0.5 & 50.97 & 9.052 & 5.213 & 95.49 \\
\hline
\end{tabular}

TABle 8: Properties of a torso phantom.

\begin{tabular}{lccccc}
\hline Parameter & Length $(\mathrm{mm})$ & Width $(\mathrm{mm})$ & Thickness $(\mathrm{mm})$ & Relative permittivity & Conductivity $(\mathrm{S} / \mathrm{m})$ \\
\hline Skin & 20 & 20 & 2 & 7.9753 & 36.397 \\
Fat & 20 & 20 & 3 & 3.1324 & 2.8152 \\
Muscle & 20 & 20 & 10 & 12.856 & 52.825 \\
\hline
\end{tabular}

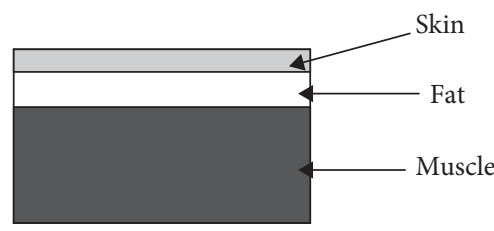

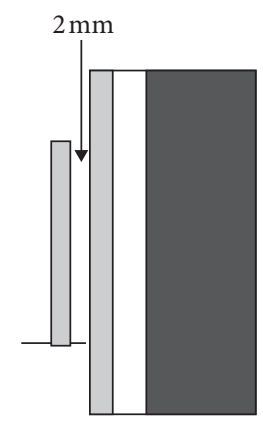

(b)

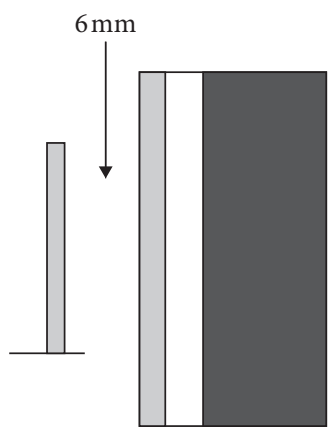

(c)

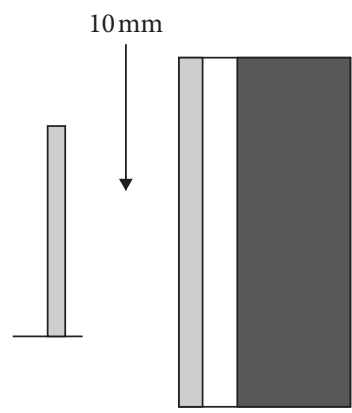

(d)

FIGURE 11: (a) Different layers of torso-equivalent torso, (b) antenna $2 \mathrm{~mm}$ away from phantom, (c) antenna $6 \mathrm{~mm}$ away from phantom and (d) antenna $10 \mathrm{~mm}$ away from the phantom.

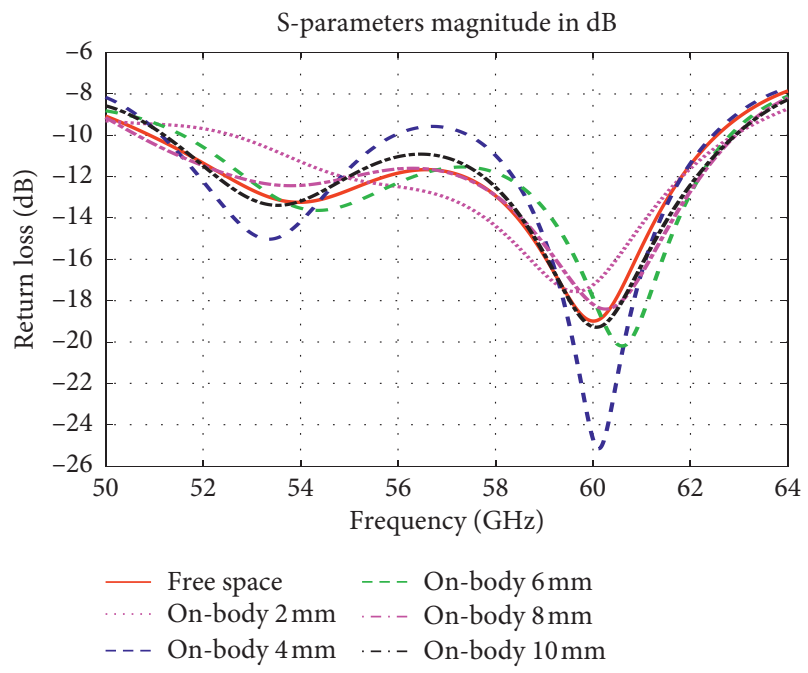

(a)

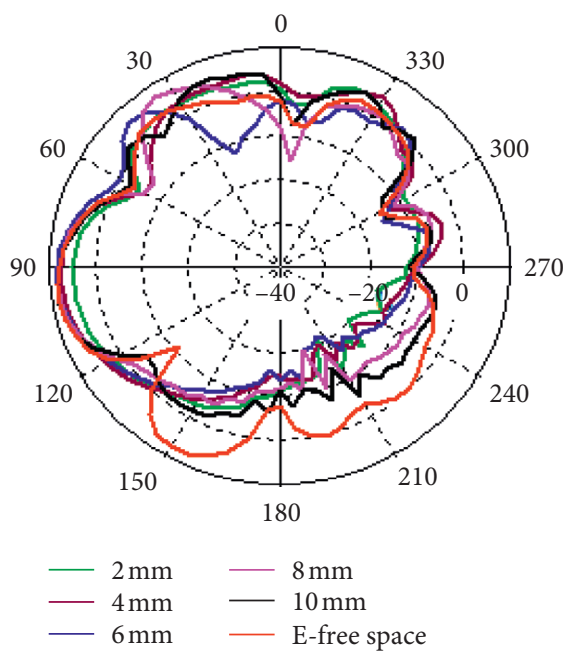

(b)

Figure 12: Continued. 


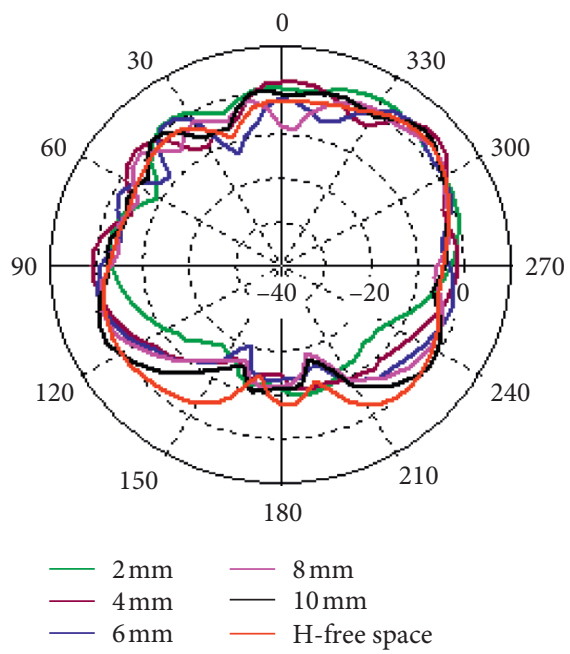

(c)

Figure 12: Polyester on-body (a) Return loss at different distances, (b) E-plane radiation patterns and (c) H-plane radiation patterns.

TABLE 9: $100 \%$ polyester on-body performance summary.

\begin{tabular}{lcccccc}
\hline Parameters & Free-space & On-body 2 mm & On-body $4 \mathrm{~mm}$ & On-body 6 mm & On-body $8 \mathrm{~mm}$ & On-body $10 \mathrm{~mm}$ \\
\hline Center frequency (GHz) & 60.01 & 59.646 & 60.122 & 60.598 & 60.262 & 60.066 \\
Bandwidth (GHz) & 11.632 & 10.271 & 5.012 & 11.225 & 12.269 & 11.71 \\
Gain (dBi) & 8.535 & 5.272 & 7.629 & 8.695 & 8.703 & 8.69 \\
Radiation efficiency (\%) & 89.4 & 63 & 69.44 & 74.06 & 78.06 & 80.65 \\
\hline
\end{tabular}

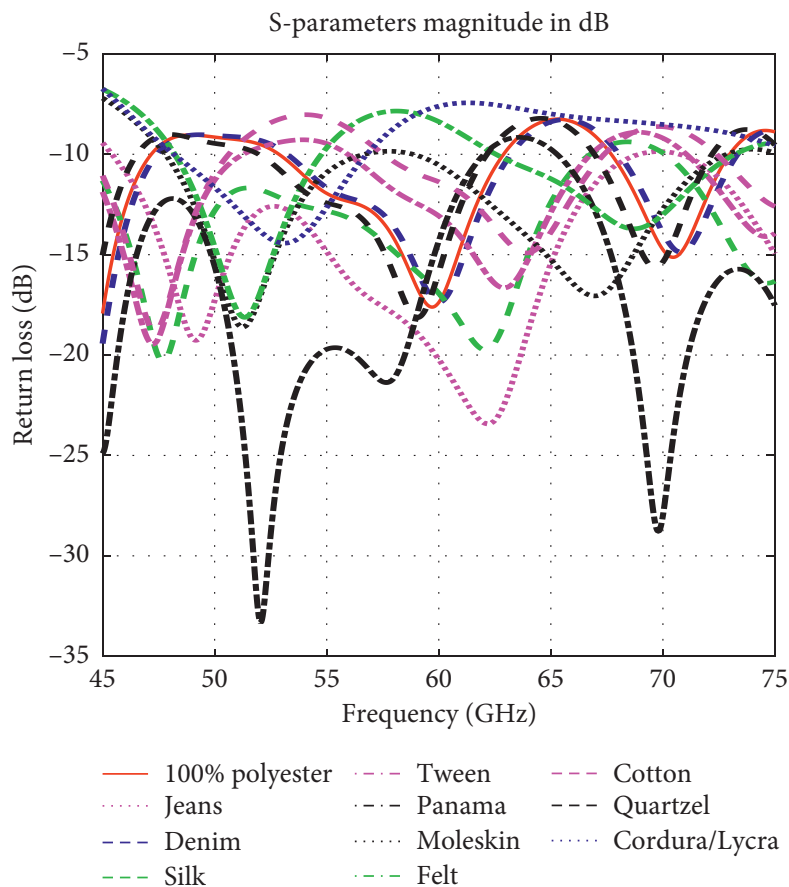

(a)

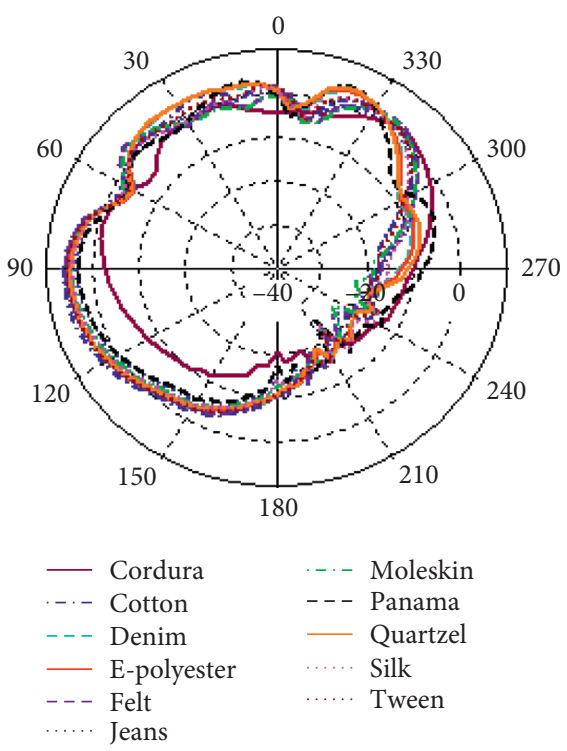

(b)

Figure 13: Continued. 


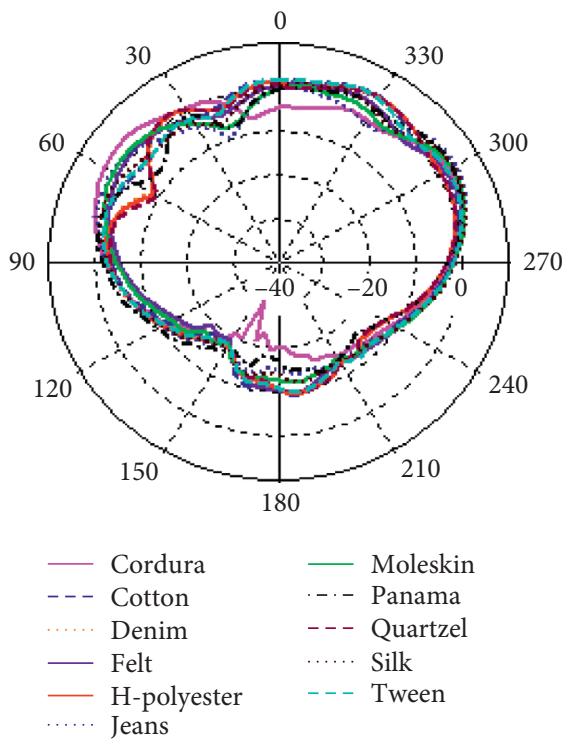

(c)

Figure 13: (a) On-body return loss responses for different textiles, (b) E-plane radiation patterns (c) H-plane radiation patterns.

TABle 10: Different textiles performance summary at $2 \mathrm{~mm}$ away from phantom.

\begin{tabular}{lcccc}
\hline Substrate & Center frequency $(\mathrm{GHz})$ & Bandwidth $(\mathrm{GHz})$ & Gain $(\mathrm{dBi})$ & Radiation efficiency $(\%)$ \\
\hline $100 \%$ polyester & 59.718 & 10.01 & 5.209 & 63.29 \\
Jeans & 62.19 & 23.51 & 4.376 & 5.239 \\
Denim & 60 & 9.962 & 4.359 & 62.93 \\
Silk & 62.135 & 22.641 & 5.280 & 50.30 \\
Tween & 62.972 & 10.484 & 4.766 & 56.08 \\
Panama & 52.05 & - & 5.674 & 50.12 \\
Felt & 68.684 & 10.681 & 4.442 & 49.82 \\
Moleskin & 66.993 & 13.98 & 5.958 & 5.75 \\
Cotton & 63.878 & 9.84 & 5.20 & 58.03 \\
Quartzel fabric & 59.04 & 10.158 & 6.658 & 64.02 \\
Cordura/Lycra & 53.13 & 8.604 & 53.86 \\
\hline
\end{tabular}

TABLE 11: Performance comparison with previous works.

\begin{tabular}{lcccccc}
\hline Reference & $\begin{array}{c}\text { Antenna dimension } \\
(\mathrm{mm})\end{array}$ & $\begin{array}{c}\text { Textile } \\
\text { substrate }\end{array}$ & $\begin{array}{c}\text { Free-space bandwidth } \\
(\mathrm{GHz})\end{array}$ & $\begin{array}{c}\text { Free-space gain } \\
(\mathrm{dBi})\end{array}$ & $\begin{array}{c}\text { On-body bandwidth } \\
(\mathrm{GHz})\end{array}$ & $\begin{array}{c}\text { On-body gain } \\
(\mathrm{dBi})\end{array}$ \\
\hline This work & $12.2 \times 12 \times 1.57$ & $\begin{array}{c}100 \% \\
\text { polyester }\end{array}$ & 11.578 & 8.531 & 10.01 & 5.209 \\
{$[18]$} & $*$ & Cotton & $57-64^{*}$ & 8.6 & $57-64^{*}$ & 7.7 \\
{$[19]$} & $26 \times 8 \times 0.34$ & Cotton & $55-64^{*}$ & 9.2 & $55-64^{*}$ & 11.9 \\
\hline
\end{tabular}

${ }^{*}$ Exact values not provided.

using denim and quartzel fabric was closest to on-body polyester performance. Figure 13(a) shows an on-body return loss comparison for all 10 different substrates along with the original polyester substrate. For denim, even though the maximum gain decreased to $5.239 \mathrm{dBi}$, the center frequency was exactly at $60 \mathrm{GHz}$ and bandwidth close to $10 \mathrm{GHz}$. With a low gain of $4.376 \mathrm{dBi}, 43.53 \%$ radiation efficiency, and center frequency of $62.19 \mathrm{GHz}$, jeans achieved the highest bandwidth of $23.51 \mathrm{GHz}$. Overall, every substrate achieved a bandwidth higher than $8.6 \mathrm{GHz}$, while the radiation efficiency never exceeded $64.02 \%$. Detailed values from the on-body analysis are given in Table 10. Figures 13(b) and 13(c) show the antenna's E and $\mathrm{H}$ plane radiation patterns for different textiles when the antenna is placed $2 \mathrm{~mm}$ away from the human body model. For changing different textile substrates, the on-body radiation patterns of the antenna change slightly; however power loss is noticed. 


\section{Comparison with Previous Works}

As mentioned previously, there aren't many $60 \mathrm{GHz}$ textile antennas studied for body-centric communications. Compared to works in $[18,19]$, the antenna proposed in this work is smaller in length but a bit wider. Overall, the dimension is a little bit more compact than other works. The bandwidth of our proposed antenna was higher in both free-space and onbody. The proposed design in this study achieved a similar result in free-space in terms of maximum gain, but for onbody, gain decreased significantly. Table 11 provides a comparative overview of our work and other known designs.

\section{Conclusions}

This paper's main purpose was to design a compact $60 \mathrm{GHz}$ antenna based on a textile substrate for body-centric communication. Designed on a $100 \%$ polyester substrate, the microstrip patch antenna showed high impedance bandwidth in the $60 \mathrm{GHz}$ band with good radiation efficiency. From parametric studies, it is shown that by decreasing the ground length, the bandwidth increases. Both gain and radiation efficiency are not affected much when changes are made in radiator and ground size. For on-body arrangement, the antenna performed best when kept at $8 \mathrm{~mm}$ away from a phantom. We have seen both bandwidth and gain increase at this distance compared to free-space with a slight degradation in radiation efficiency. The antenna's lowest gain was at the closest distance from the phantom. In general, the antenna's performance kept on improving as the distance between the phantom and the antenna kept on increasing.

Their relative permittivity value characterizes textile substrates. This was evident as the antenna performed equally well when the polyester substrate was replaced by denim, tween, or quartzel fabric. Compared to previous works on $60 \mathrm{GHz}$ textile antennas, our design achieved higher impedance bandwidth. Even though the free-space gain was similar, the on-body gain was much lower. There are not many textile antennas designed for $\mathrm{mm}$-wave wearable devices. Our work will be a good addition to this class of antennas because of its compact and relatively simple design.

\section{Data Availability}

The data used to support the findings of this study are freely available at http://niremf.ifac.cnr.it/tissprop/

\section{Conflicts of Interest}

The authors declare that they have no conflicts of interest to report regarding the present study.

\section{Acknowledgments}

The authors are thankful for the support from Taif University Researchers Supporting Project (TURSP-2020/239), Taif University, Taif, Saudi Arabia.

\section{References}

[1] T. S. Rappaport, G. R. MacCartney, M. K. Samimi, and S. Sun, "Wideband millimeter-wave propagation measurements and channel models for future wireless communication system design," IEEE Transactions on Communications, vol. 63, no. 9, pp. 3029-3056, 2015.

[2] P. S. Hall and Y. Hao, "Antennas and propagation for body centric communications," in Proceedings of the 2006 First European Conference on Antennas and Propagation, pp. 1-7, Nice, France, November 2006.

[3] T. Guo, R. C. Qiu, S. S. Mo, and K. Takahashi, " $60 \mathrm{GHz}$ millimeter-wave radio: principle, technology, and new results," EURASIP Journal on Wireless Communications and Networking, vol. 2007, Article ID 068253, 2006.

[4] A. M. Al-samman, M. H. Bin Azmi, and T. A. Rahman, "A survey of millimeter wave (mm-wave) communications for 5G: channel measurement below and above $6 \mathrm{GHz}$," in Recent Trends in Data Science and Soft Computing, F. Saeed, N. Gazem, F. Mohammed, and A. Busalim, Eds., vol. 843Berlin, Germany, Springer, 2019.

[5] H.-B. Li, K.-I. Takizawa, B. Zhen, and R. Kohno, "Body area network and its standardization at IEEE 802.15.MBAN," in Proceedings of the 16th IST Mobile and Wireless Communications Summit, pp. 1-5, Budapest, Hungary, July 2007.

[6] J. Tak and J. Choi, "An all-textile louis vuitton logo antenna," IEEE Antennas and Wireless Propagation Letters, vol. 14, pp. 1211-1214, 2015.

[7] B. Almohammed, A. Ismail, and A. Sali, "Electro-textile wearable antennas in wireless body area networks: materials, antenna design, manufacturing techniques, and human body consideration-a review," Textile Research Journal, vol. 91, no. 5-6, pp. 646-663, 2020.

[8] T.-W. Koo, Y.-J. Hong, G.-K. Park, K. Shin, and J.-G. Yook, "Extremely low-profile antenna for attachable bio-sensors," IEEE Transactions on Antennas and Propagation, vol. 63, no. 4, pp. 1537-1545, 2015.

[9] M. M. Khan, Q. H. Abbasi, A. Alomainy, C. Parini, and Y. Hao, "Dual band and dual mode antenna for power efficient body-centric wireless communications," in Proceedings of the IEEE International Symposium on Antennas and Propagation (APSURSI), pp. 396-399, Spokane, WA, USA, July 2011.

[10] M. M. Khan, Q. H. Abbasi, and R. H. Ashique, "Comprehensive design and propagation study of a compact dual band antenna for healthcare applications," Journal of Sensor and Actuator Networks, vol. 4, no. 2, pp. 50-66, 2015.

[11] B. Yeboah-Akowuah, P. Kosmas, and Y. Chen, "A Q-slot monopole for UWB body-centric wireless communications," IEEE Transactions on Antennas and Propagation, vol. 65, no. 10, pp. 5069-5075, 2017.

[12] Q. H. Abbasi, M. M. Khan, S. Liaqat, M. Kamran, A. Alomainy, and Y. Hao, "Experimental investigation of ultra wideband diversity techniques for on-body radio communications," Progress in Electromagnetics Research C, vol. 34, pp. 165-181, 2013.

[13] S. F. Jilani, M. O. Munoz, Q. H. Abbasi, and A. Alomainy, "Millimeter-wave liquid crystal polymer based conformal antenna array for 5G applications," IEEE Antennas and Wireless Propagation Letters, vol. 18, no. 1, pp. 84-88, 2019.

[14] K. Islam, T. Hossain, M. Monirujjaman Khan, M. Masud, and R. Alroobaea, "Comparative design and study of a $60 \mathrm{GHz}$ antenna for body-centric wireless communications," 
Computer Systems Science and Engineering, vol. 37, no. 1, pp. 19-32, 2021.

[15] K. Islam, T. Hossain, and M. M. Khan, "A compact novel design of a $60 \mathrm{GHz}$ antenna for body-centric communication," International Journal on Communications Antenna and Propagation (IRECAP), vol. 10, no. 5, pp. 325-333, 2020.

[16] J. Puskely, M. Pokorny, J. Lacik, and Z. Raida, "Wearable disclike antenna for body-centric communications at $61 \mathrm{GHz}$," IEEE Antennas and Wireless Propagation Letters, vol. 14, pp. 1490-1493, 2015.

[17] M. Ur-Rehman, N. A. Malik, X. Yang, Q. H. Abbasi, Z. Zhang, and N. Zhao, "A low profile antenna for millimeter-wave body-centric applications," IEEE Transactions on Antennas and Propagation, vol. 65, no. 12, pp. 6329-6337, 2017.

[18] N. Chahat, M. Zhadobov, S. A. Muhammad, L. Le Coq, and R. Sauleau, " $60 \mathrm{GHz}$ textile antenna array for body-centric communications," IEEE Transactions on Antennas and Propagation, vol. 61, no. 4, pp. 1816-1824, 2013.

[19] N. Chahat, M. Zhadobov, L. Le Coq, and R. Sauleau, "Wearable endfire textile antenna for on-body communications at $60 \mathrm{GHz}$," IEEE Antennas and Wireless Propagation Letters, vol. 11, pp. 799-802, 2012.

[20] M. Mohamed, M. B. El_Mashade, S. Berra, G. S. Gaba, and M. Masud, "A novel hybrid precoding-companding technique for peak-to-average power ratio reduction in $5 \mathrm{G}$ and beyond," Sensors, vol. 21, no. 4, p. 1410, 2021.

[21] S. Yan, V. Volskiy, and G. A. E. Vandenbosch, "Compact dual-band textile PIFA for $433 \mathrm{MHz} / 2.4 \mathrm{GHz}$ ISM bands," IEEE Antennas and Wireless Propagation Letters, vol. 16, pp. 2436-2439, 2017.

[22] M. Hirvonen, C. Böhme, D. Severac, and M. Maman, "Onbody propagation performance with textile antennas at $867 \mathrm{MHz}$," IEEE Transactions on Antennas and Propagation, vol. 61, no. 4, pp. 2195-2199, 2013.

[23] M. Klemm and G. Troester, "Textile UWB antennas for wireless body area networks," IEEE Transactions on Antennas and Propagation, vol. 54, no. 11, pp. 3192-3197, 2006.

[24] H. Lee, J. Tak, and J. Choi, "Wearable antenna integrated into military berets for indoor/outdoor positioning system," IEEE Antennas and Wireless Propagation Letters, vol. 16, pp. 1919-1922, 2017.

[25] P. M. Potey and K. Tuckley, "Design of wearable textile antenna with various substrate and investigation on fabric selection," in Proceedings of the 3rd International Conference on Microwave and Photonics (ICMAP), pp. 1-2, Dhanbad, India, February 2018.

[26] M. El Bakkali, M. El Bekkali, G. S. Gaba, J. M. Guerrero, L. Kansal, and M. Masud, "Fully integrated high gain S-band triangular slot antenna for CubeSat communications," Electronics, vol. 10, no. 2, p. 156, 2021.

[27] A. K. Bairagi, M. S. Munir, M. Alsenwi et al., "Coexistence mechanism between eMBB and uRLLC in 5G wireless networks," IEEE Transactions on Communications, vol. 69, no. 3, pp. 1736-1749, 2021.

[28] IFAC (International Federation of Accountants), Dielectric Properties of Body Tissues in the Frequency Range $10 \mathrm{~Hz}$ to $100 \mathrm{GHz}$, Italian National Research Council, Rome, Italy, 2021. 